\title{
THE OUTCOMES OF A STRUCTURAL REFORM IN HAAPSALU NEURO- LOGICAL REHABILITATION CENTRE (ESTONIA) BETWEEN 2016 AND 2017
}

\author{
Mari-Liis Ööpik-Loks,2, Justina Bernyte ${ }^{1}$, Priit Eelmäe ${ }^{1,2}$. \\ ${ }^{1}$ Haapsalu Neurological Rehabilitation Centre, Haapsalu, Estonia \\ ${ }^{2}$ Centre of Excellence in Health Promotion and Rehabilitation, Haapsalu, Estonia
}

\section{BACKGROUND:}

Haapsalu Neurological Rehabilitation Centre (HNRC) is a modern rehabilitation hospital in Estonia with 102 beds for adults and children with various neurological disorders

Until the end of 2016 the structure of the hospital was based on professions. In order to follow the core values of the hospital - patient-centeredness, quality, innovation and co-operation and with the aim of increasing the number of acute phase patient cases, a structural reform was undertaken between 2016 and 2017. During the reform, diagnose-based departments were created while planning tasks were decentralized each new unit being responsible for their own patient selection and bed allocation. As a result of the reform, the team of specialists dedicated to one patient belong to the same department which should improve patient-centeredness, information exchange and cooperation between the professionals.

\section{AlM:}

The aim of the current study was to determine the influence of the structural change on patient selection, bed planning and patient involvement in active therapies.

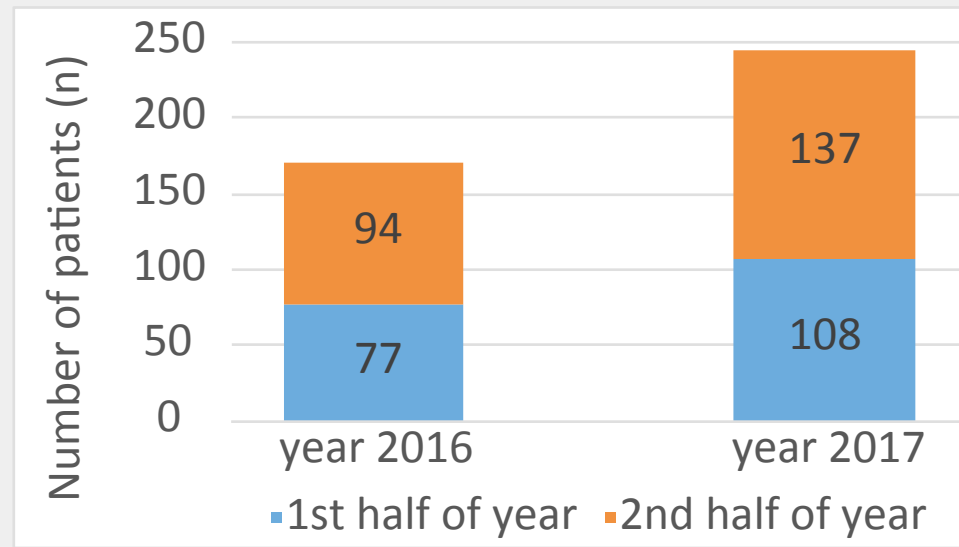

Figure 1. Number of acute patients in department of neurorehabilitation at 2016 and 2017 year

\section{SUBJECT AND METHODS:}

The study was held in the Department of Neurorehabilitation of HNRC, where there are 38 inpatient beds mainly for stroke but also traumatic brain injury patients. The data was collected from the medical database of HNRC, comparing the cases of acute phase patients whose rehabilitation period was longer than 12 days.

In Estonia, acute phase is considered 6 months post stroke and 18 months after TBI during which the Estonian Health Insurance Fund, the main funder of HNRC's services with about $70 \%$ of the budget, covers rehabilitation services of extended duration - depending on the patient's condition from 14 to 21 days which in certain cases can also be extended respectively.
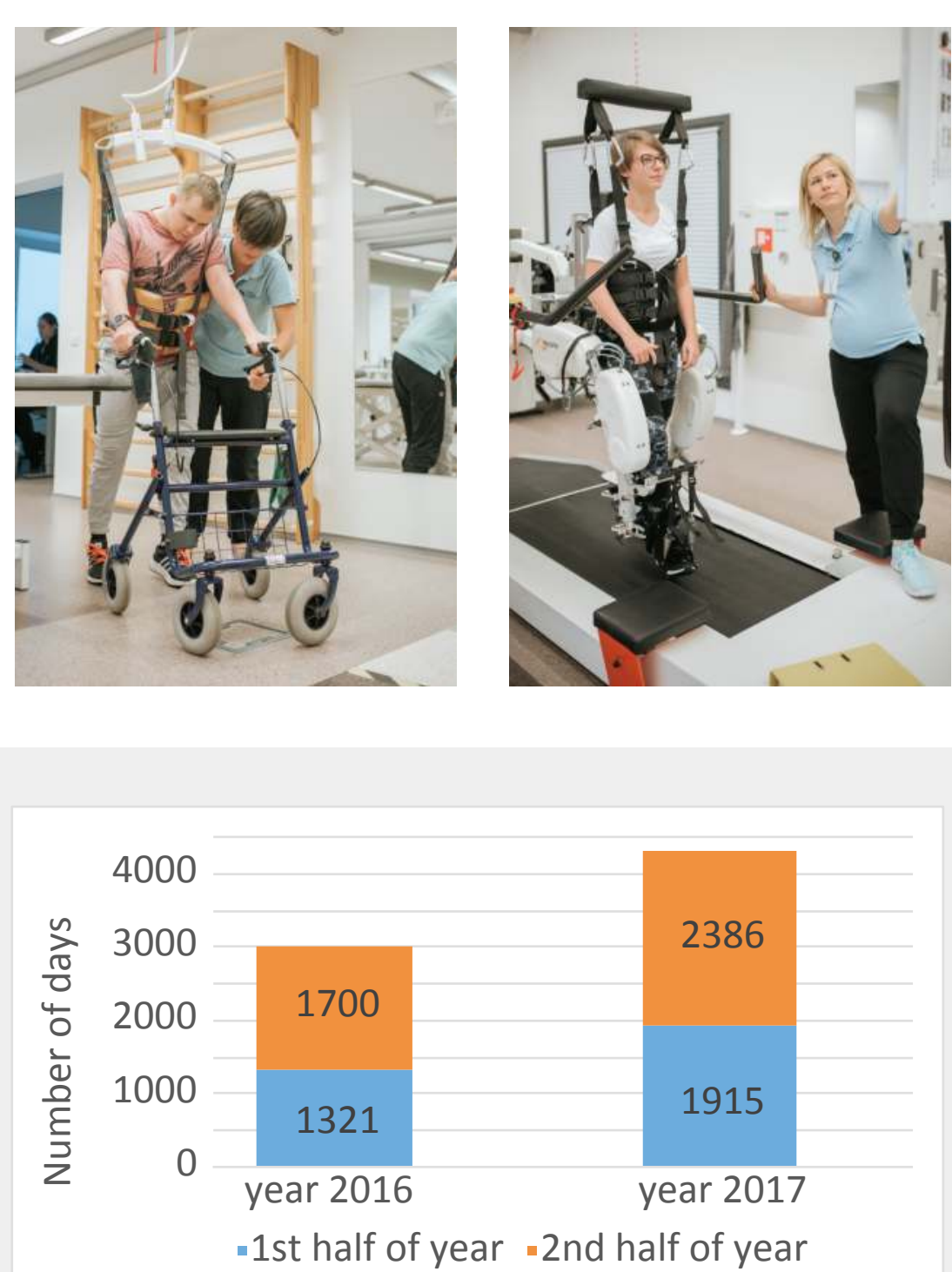

Figure 2. Number of hospital days of acute patients in department of neurorehabilitation at 2016 and 2017 year.
One of the aims of the structural reform was to increase the number of acute patient cases through improved planning and patient selection processes.

\section{RESULTS:}

The number of acute phase cases in the Department of Neurorehabilitation increased from 171 to 245 between 2016 an 2017, by 43.27\% (Figure 1). The number of hospital bed days increased by 42.37\% from 3021 to 4301 respectively (Figure 2).

In 2016, the patients were involved in active therapies on average of 123.94 minutes per day, including the weekends, in 2017 the active time was increased to 131.83 minutes per day (Figure 3). Active therapies include physiotherapy, occupational therapy, speech and language therapy and psychotherapy

\section{CONCLUSIONS:}

Based on the results above, the structural reform has had a positive influence on the management of the hospital, resulting in increased number of acute phase patient cases, hospital bed days and patients' involvement in active therapies.

\section{HNRC's structure}

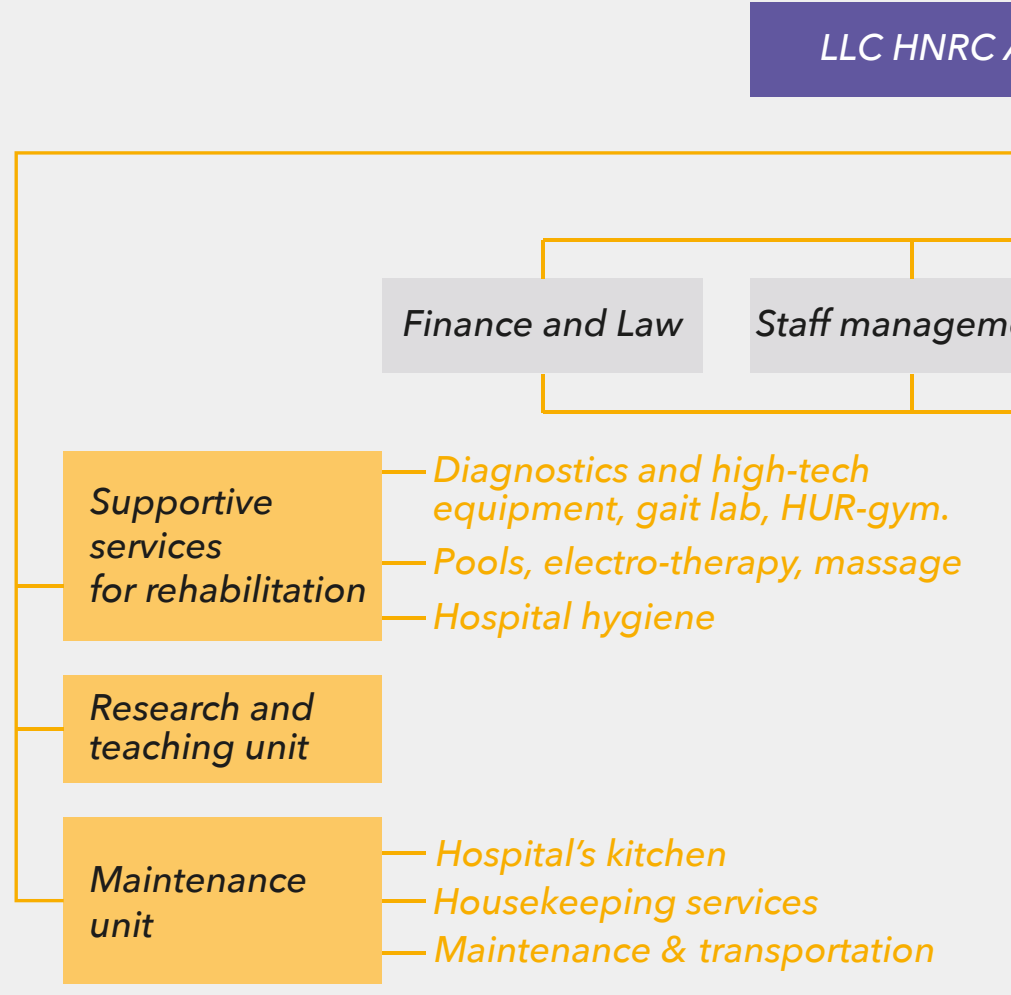

$B O A R D$

Board's office

\section{Administration} and events
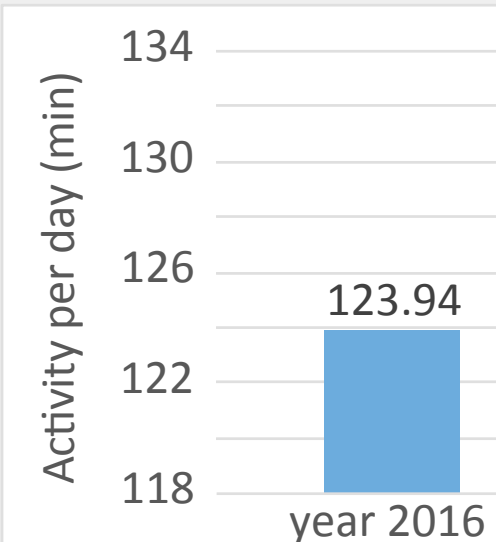

131.83

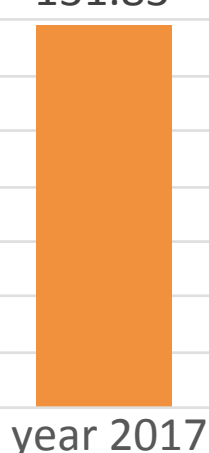

Figure 3. Patients involved in active therapies (minutes per day, including the weekends) in department of neurorehabilitation at 2016 and 2017 year (average).

provision

Communication and marketing

Quality and development

IT and data
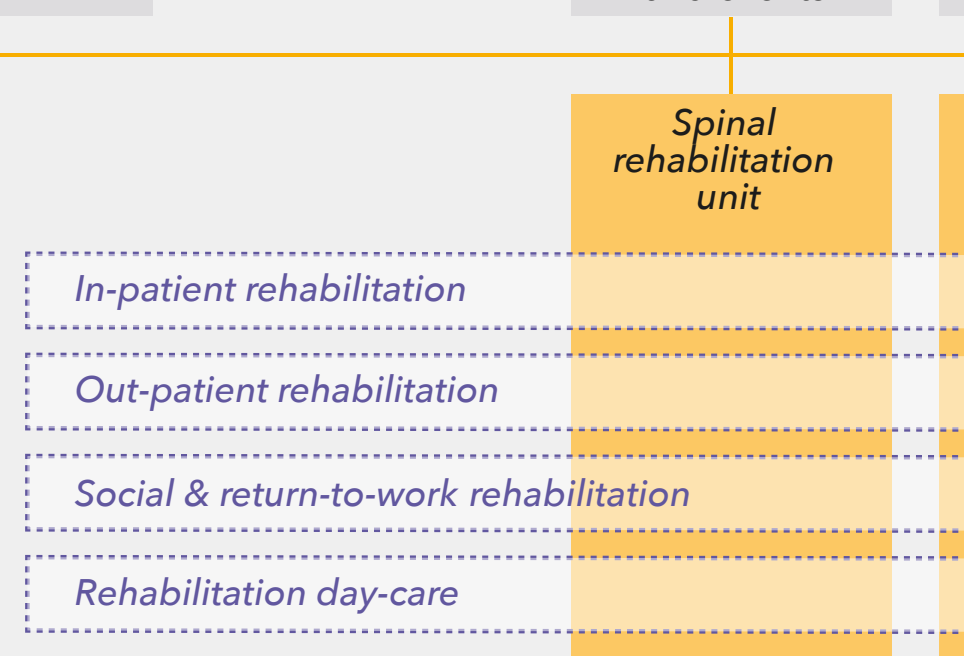